Journal of Computer Science 2 (7): 558-564, 2006

ISSN 1549-3636

(C) 2006 Science Publications

\title{
Task Collaborative Resolution Tool for Elearning Environment
}

\author{
${ }^{1}$ Samir Zidat and ${ }^{2}$ Mahieddine Djoudi \\ ${ }^{1}$ Department of Computer Science, University Hadj Lakhdar of Batna, Algeria \\ ${ }^{2}$ ERTe IRMA \& Laboratoire SIC, University of Poitiers Bât. SP2MI, Téléport 2, Bv. Marie et Pierre Curie \\ BP 3017986962 Futuroscope Chasseneuil Cedex, France
}

\begin{abstract}
In this article, we are interested in the tasks collaborative resolution in elearning context, and in the use of information technology to support this activity. A part of this article is devoted to the modeling of the activity of tasks collaborative resolution. Then, we suggest an approach for the automatic perception of the good quality of the users' contribution. This approach is mainly based on the design of an on-line tool of tasks resolution using the semi-structured resolution by acts of language. The environment should also allow the fast perception of the complete progress of the session of tasks resolution and thus facilitating comprehension of the solution suggested for learners.
\end{abstract}

Key words: Task collaborative resolution, collaborative learning, participation quality

\section{INTRODUCTION}

The tasks resolution in the current environments of distance learning is often achieved individually. The interactions between learners are rarely occurring in these platforms.

Though they constitute a key factor in the process of learning ${ }^{[1]}$. Even though the environment offers diversified tools of communication, these latter are little used in the activities of learning. Participation and the interaction between students remain limited enough ${ }^{[2,3]}$. Rada and Wang underlines in $^{[4]}$, the heaviness of the process of distance collaboration: Some university students expressed little interest to share their work with their colleagues. Fung ${ }^{[5]}$ claims that the distant learners, following a course developed according to the pedagogy by project, are working in an individual way. These latter suffer from the isolation imposed upon them and this constitutes an obstacle to achieve their tasks. This study supports the recommendation of Peal and Wilson affirming in ${ }^{[6]}$ that the individualized activities of learning must be integrated in a wider network formed of learners in interaction. To favor this type of interactions in an environment of resolution of tasks at distance, we think, like George ${ }^{[7]}$, that it would be necessary to:

* design tools more adapted to the exchange of the speeches or resources between students;

* create teaching situations favoring the emergence of the interactions between students.

The context of our work is marked by the will to set up distant activities of cooperative learning, which are based on the tasks collaborative resolution and the use of information technology to support these activities. We can define the tasks collaborative resolution as being a way of exchanging and sharing knowledge / information that might take place during the learners' interactions ${ }^{[8-9]}$.
A part of our work consists in clarifying and modeling the activity of collaborative resolution of tasks. Our model relies on a human organization into a team composed of learners with or without a tutor and they are sharing the resolution of the same activity. Also, a distant teacher can ensure the supervision of the task resolution and assisting his/her learners in their task.

The other part of our work consists in assessing automatically our learners' contributions during the distant collaborative resolution of tasks. We propose a particular approach to analyze the learners' interactions; these latter can reveal positive contributions that are worth to be singled out.

The current nature of the environments of distance learning is rather static, their structure being predefined in advance by the designers ${ }^{[10]}$. The resolution of tasks in our case is an adequate framework to embark the students on a dynamic of group. We, thus, create the ideal conditions for the emergence of an interaction between students who are rich enough from an educational point of view. Also, we make available the suitable resources by providing functionalities of access to students, in particular to consult tasks solved beforehand.

Among the important points of our contribution, we place at the disposal of the learners an editor of writing of solution under HTML format. The task can be of simple form requiring a solution whose statement is of simple form. In case a task requires a detailed analysis and a division in more refined levels, our editor lends itself to it suitably by structuring the analysis of the task like its solution in the form of tree structure. We create, thus, an environment of collaborative production facilitating the resolution of tasks and allowing the creation of social links between the learners. We, thus, hope to contribute to fight against the isolation of the learners and to offer a true 
assistance to the management of the working sessions. While designing our tool, we were inspired by the traditional practices, which already showed their effectiveness, and we should profit from the various techniques and the new tools available, which make tasks easier for the learners.

\section{TASKS RESOLUTION}

What is a task? A task can be characterized as a process of research constituting a challenge for the resolver (learner), who mobilizes aptitudes, skills, knowledge and faculties of comprehension to face and solve problems never met before. Such a task should be neither too easy nor too difficult; otherwise it does not stimulate the reflexion of the student or totally discourages him. On the other hand, the selection and the choice of the nature of the tasks should be judicious in order to meet and satisfy the teacher's objectives.

Why do we use tasks? Teaching through tasksituations is appreciated more and more nowadays. Because it gives much more sense to the teaching material, the students can reinvest their acquired knowledge and strengthen it. Furthermore, the teaching and learning situation is becoming coherent. Thus, the learning teaching situation is viewed as a process of developing and acquiring knowledge through different types of interaction while trying to resolve the suggested task.

What is a method of resolution of tasks? There is no universal method of resolution. Each statement is, for the resolver, a new challenge. Nevertheless, in any method of resolution of tasks one distinguishes usually the three following stages:

* Understanding the issue

* Conceiving a plan

* Executing the plan

The experiment shows that the students tend not to respect the previous three mentioned stages. That is why the teacher should emphasize the first stage, which are the familiarization and the understanding of the issue. Without favoring a particular strategy of resolution, the teacher invites the students to read well the task, in order to find out what is given (the assumptions) and which is to be found (unknown factors) or to prove (the thesis). The listing of the considerations caused then by the statement, as well as putting into practice the best ideas met, will lead to the design of a plan and, finally to the checking and the editing of the answer. The organization of the class in groups is highly recommended in such cases.

\section{TASK COLLABORATIVE RESOLUTION}

We are aware of the absence of an explicit social study, which is effectively able to determine the team's needs which is engaged in a process of collaborative tasks resolution.

The members of the group are prone to a complex sequence of mutual influences due to their personal differences (competencies, personalities, etc). Each learner is characterized by his/her specific and particular strategies of resolution, which can evolve on the basis of interaction between the various members of the team. Difficulty generated with the modeling of the process of resolution collaborative results from the fact that some of these activities can be neither observed nor described, as for example the important part of this process which the students, engaged in the resolution, dedicate to the mental effort ${ }^{[11]}$.

It is quite impossible to develop on-line support taking into account all these aspects. Nevertheless, some studies ${ }^{[9,12,13]}$ and our modest experience in the field of teaching (more than twenty years in field of teaching), supplied us with valuable and sufficient data to single out some useful characteristics in the development of an appropriate supporting tool.

The experimentation of this tool will, later, reveal the difficulties to overcome and as well as the necessary changes/corrections to be brought. The design of our data-processing tool is based on the metaphor of the blackboard $^{[14]}$. Indeed, in a traditional room of stages, the blackboard has a major role in the resolution of tasks.

A stage often consists of a series of tasks. With this metaphor, the learners try to solve the task within a group. A volunteer or a appointed learner, qualified as a principal writer of the solution, passes to the blackboard and suggests a resolution plan of the tasks, by specifying the assumptions provided by the statement of the task and the unknown factors to be found or the thesis to be proven.

\section{TASK RESOLUTION MODEL}

The distant collaborative resolution of tasks consists of two complementary structures:

* The first, of linear nature, represents the blackboard. Each node corresponds to an attempt of resolution leading to the final solution on behalf of the principal writer (the learner at the blackboard).

* The second, of tree form, records all the debate initiated by the proposal for a new attempt of task resolution. Each node records any intervention or contribution emitted by a learner.

The tree structure is widely used in the asynchronous forum of discussion. The main objective is to link each message to the one-it responses or reacts. The new subjects of discussion are placed at the root of the tree and represent the first reactions of the attempt to solve task, the others being hung up again with the existing messages. 


\begin{tabular}{|l|l|l|l|l|l|}
\hline Category & Initiative & Reactive & Auto-reactive & Evaluative & Guidance only for a tutor \\
\hline Act & Propose & Respond & Precise & Approve & Reformulate \\
& & Question & Rectify & Disapprove & Supply \\
& & & Encourage (valid) & Invite \\
& & & & Orient
\end{tabular}

Table 1: Displaying category and acts of resolution tool

\begin{tabular}{|c|c|c|c|}
\hline \multicolumn{2}{|c|}{ Pair interventions } & \multicolumn{2}{|l|}{ Examples } \\
\hline First part & Second part & Intervention of $\mathrm{A}$ & Reaction of B \\
\hline Propose & $\begin{array}{l}\text { Approve } \\
\text { Disapprove } \\
\text { Question }\end{array}$ & I propose the following solution by using a chained list. & $\begin{array}{l}\text { - Yes, I agree. } \\
\text { - No, Not immediately } \\
\text { - Why not a table? }\end{array}$ \\
\hline Answer & $\begin{array}{l}\text { Approve } \\
\text { Disapprove } \\
\text { Question }\end{array}$ & Table structure is not adequate. We don't know the number of elements. & $\begin{array}{l}\text { - Oh, yes } \\
\text { - You are not right } \\
\text { - And the pile? }\end{array}$ \\
\hline Question & $\begin{array}{l}\text { Answer } \\
\text { Question }\end{array}$ & Which pointer? & $\begin{array}{l}\text { - The one at the top } \\
\text { - There are many? }\end{array}$ \\
\hline Approve & $\begin{array}{l}\text { Approve } \\
\text { Disapprove } \\
\text { Question }\end{array}$ & I agree with Salah's development & $\begin{array}{l}\text { - So, do I } \\
\text { - I disagree } \\
\text { - Which development? }\end{array}$ \\
\hline Disapprove & $\begin{array}{l}\text { Approve } \\
\text { Disapprove } \\
\text { Question }\end{array}$ & I do not agree with the development of Salah? & $\begin{array}{l}\text { - Yes, I also disagree } \\
\text { - Me, I agree. } \\
\text { - Why? }\end{array}$ \\
\hline
\end{tabular}

Table 2: Sequence of actions in the resolution tool

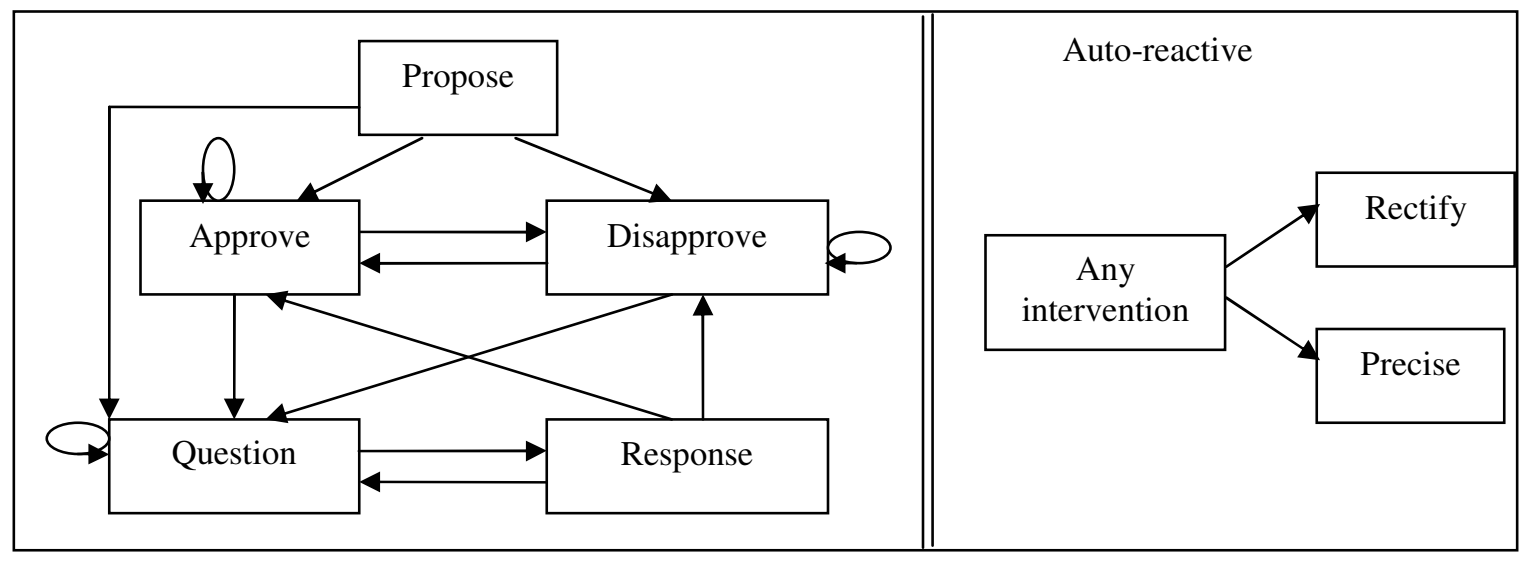

Fig. 1: Chain-like of actions sequence in the resolution tool

The advantage of this representation is to hold account of succession of discussion and thus of the topics for the conversation. Any message lately added to our forum is labeled by an option of menus; this label identifies the linguistic action (to answer, to agree, to disagree or to question, to precise or to rectify) (Table 1). The options of menus are available according to the selected reaction of the participant compared to an intervention already recorded but authorized by the sequence of actions in the resolution tool (Table 2).

To avoid the confusion of the participants, only one student is, at the certain time, authorized to send his/her message. Any student has to ask for permission by emitting a request of participation. Once this latter is satisfied/accepted by the tutor, in case the teacher is present or each one has a turn in case in the absence of the teacher.

For each intermediate solution, the principal writer engages an interaction with classmates through our synchronous forum, to defend and clarify his/her argument(s). At the end of the interaction, all the classmates adopt a solution or a new version is proposed and the process of continuous resolution is taken place until reaching a final version of the solution. 
The structure of the forum enables the participants to identify of points of coordination in the debate started during the resolution. We think, by using our tool, that the learners acquire new competencies in terms of collaborative work. The fact of characterizing his/her intervention in form of a "question" or an "answer" drives the learner to think and reconsider "the act that he/she is realising" and therefore, will give an educational value and improves the state of progress of task resolution.

In our resolution model we join, partly, the research work of ${ }^{[15-19]}$ which allow the specification and modeling the collective environment model. Our contribution is to adapt these research results, which treat conversation models by acts of language in the context of distant task resolution.

We have to mention that the resolution session can be proceeded with or without a teacher. By adding a new category of language acts entitled "guidance" specific to the tutor, we, then have enriched the model to take into account the dimension of tutoring a task resolution session. By the way, according to our research, we were unable to find already made work referring to that.

We have opted for a very general classification by reducing the acts of the initiative category to only one act, which is "To propose". Indeed, we think this kind of classification is simple and more adequate, taking into consideration our two objectives, which consist of providing the participants with a model of interactions. Thus, the facilitating the debate that was initiated by the principal writer and therefore, evaluating the quality of participation of each learner.

We define the acts of language of our resolution tool as displayed in Table 1 and we define Chain-like of actions sequence in the resolution tool as displayed in Table2.

The principal writer proposes a solution. One participant Approves, disapproves or questions.

* Any question is automatically followed either by a response, or a new question.

* Any response is automatically followed either by an approval, disapproval or a question.

* Any approval/disapproval is automatically followed either by an approval, disapproval or a question.

The teacher can use several well-known methods of intervention:

* Reformulating the learner's statement so that to make it clear to all participants.

* Encouraging the participant by annotating his contribution by an expression such as "Well done!"- "Wonderful!" -“Excellent", etc.

Supplying the learner with more information besides that the tutor can put hyperlinks towards some parts of the courses that might help the learner. Dynamic attribution of roles: We prefer the concept of role to that of right because it seems more significant to us. The fact of having a right does not explain which a person is going to use it (example: if a participant has a right of reading on an element of the resolution, is it to inquire about its contents, to criticize it, or to confirm it?). This attribution and/or modification of roles can be made at any time during the phase of collaborative resolution. The attribution of roles (principal editor, and participant) in our tool is thus dynamic.

Tutor: When a tutor allots roles of participation in the task resolution, he has the visibility on all the production of the resolution. In fact, the attribution of roles must be seen like a mechanism allowing the management of the meeting of virtual rooms, and to control the accesses. The tutor as a fine and effective means allowing the control of the students can perceive the attribution. He can, in addition, note in a visible way the quality of each individual contribution (quality of the solution, relevance of the question) to enable him to collect sufficient data to appreciate the level of integration and the working method of a learner in a group.

Participant in the solution: Allows the learner to analyse and criticize the version of the solution suggested by the principal editor. He can thus raise or answer a question or make an approval/disapproval during the debate started by the group whose work is to solve the task. He can also solicit to become the principal editor of the solution of the task.

The main editor of the solution: Allows the learner during a specific stage of the process of resolution to propose his solution. Then, there is a cooperative debate to discuss this last one, to analyse it, to criticize it and to enrich it. The student editor can so draft a new version of the solution by taking into account the contribution of his companions. This process, proposition of solution followed by debate, will be repeated until the final version. So, an editor is loaded (charged) to propose a version of the solution (intermediate or final) via the tree of resolution, to ask a question, answer a question or make a comment during the debate initiated by the group of which task is to resolve an exercise through the forum of discussion.

\section{APPRECIATION OF CONTRIBUTION QUALITY}

The observation grids used enable the tutor to gather the needed information about any learner in terms of (competencies and /or conceptions, etc...) throughout a pedagogical activity (course).

Once learners are engaged in collaborative task in groups, certain dynamism is set up gradually and within this dynamism each partner can identify his/her position within the group, according to his/her personal capacities. The learners are helping one another; this kind of help is based upon each learner's competencies and attitudes. 
These observations provide the tutor with valuable information that helps him/her to form a clear image about his/her learners, which constitutes a cornerstone for the success of a distant learning process. Thus, reducing the number of the abandonment due to the feeling of being isolated. A same time, it helps the learners to know one another in terms of abilities and competencies so that to better their exchanges or profit from one another.

For obtaining easily the needed information about learner, we think we are in a need for a tool, which is capable to evaluate automatically the learners' contributions in case the tutor is absent. On the other hand, if the tutor is present our tool enables him/her to annotate the positive learner's contribution.

Another possibility of the usage of this valuable information is permitting us to create interesting pedagogical conflicts by selecting the level of the learner newly joining the group. On the other hand, the learner can value himself/herself thanks to the information about his/her contribution provided by the tool. At the end our suggested tool can provide a learner with a whole idea about process resolution

Automatic appreciation: When attempting to automatically evaluate the participation quality of the learners while they are engaged in the collaborative resolution of tasks, our objective is not to obtain a complete answer of this delicate subject but we wish to have an approach supplying us some elements of the needed information. We propose here three criteria, which we are used to identify a positive contribution:

Any contribution causing an important reaction from different participants is considered as a positive one; resulting in a debate even this latter does not lead to the requested solution.

To defend this first criterion, we hypothesize that the task resolution is not an end in itself from the teaching point of view; it is only a means and a framework of reflexion where learners can broaden and deepen their knowledge. We also assume that an important reaction is the one that results in obtaining from learners at least three questions and three answers. Any approved answer for any question that is obtained during the debate is considered as a second criterion. This latter can depict any important intervention that supplies us with clarification in form of answers to asked questions.

\section{Question $\rightarrow$ Answer $\rightarrow$ Approval}

Any favorably annotated contribution by the tutor is considered as the final and an obvious criterion in case the tutor is supervising the resolution session.

CHARACTERISTICS OF THE TOOL
The success of the cooperative resolution can be measured with the way in which our tool is able to create and to support a good group dynamics. This one must thus contribute to make disappear virtuality from presence of the learners. Work must be able to proceed at least as naturally as in face to face and without the data-processing support. It must even profit from an organization of more effective work being based on the new possibilities offered by data processing. This organization constitutes an ideal ground for the modeling of the communication, coordination and the co-operation between the learners.

Our tool should disturb neither the collaborative process of the resolution of the task nor the created dynamic of the group. When designing our tool, we are aware that the dimension use, which validates it, is at least as important as dimension realization (engineering). Thus, we particularly intend through the design of the tool to answer a certain number of needs dictated by the process of collective tasks resolution, which we will be detailed later.

To support the cohesion of group: Our tool associates with each task of seminars, a group of learners designated to the development of the associated solution. The application helps the participants to know one another by allowing them access to their social and organisational information (statuses, roles). Moreover, our tool, through the functionality of Rendezvous, provides to the tutor a means of maintaining cohesion of the group by imposing rates/rhythms of work to the group and by specifying a scheme of work to accelerate the process of decision-making.

To improve the learners' competencies: Refusal to be integrated into a group is mainly due to a fear to belittle. To avoid nourishing this type of fear, we integrate the learners in their natural environment. The availability of the tools of communication enables the learner, at any moment, to request the assistance of his teacher or of his colleagues. Thus, we encourage the various contributions of the learners without regard to their level and their competencies. This exchange will inevitably result in creating an ideal space for the acquisition and the exchange of the knowledge.

To improve cooperative Learning: Our tool is an element that fits suitably in the platforms of cooperative learning assisted with computer. It is, thus, at the same time a system of training and software of work of group. We designed a model centered on the user and his/her interactions with the others, in a teaching environment. Our model is an instrument, i.e. the on line tool intended to support the interactions, the communication, collaboration or the cooperation between the users. Organized in groups, the users have a common objective, which is, in our training situation, the implementation and the management of a room of 
virtual seminars, whose vocation is to constitute a space favorable for the task resolution.

It is therefore, a groupware as far as; it is going to assist groups of users in the realization of their common

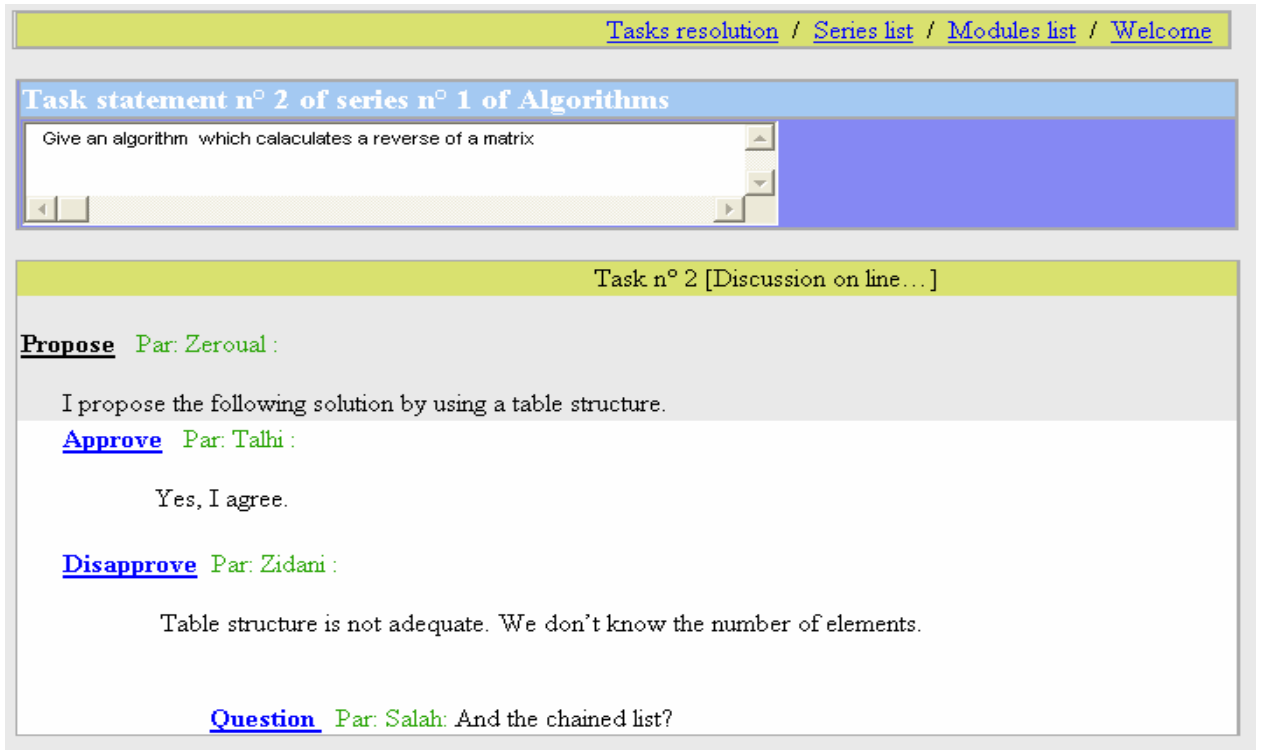

Fig. 2: Example pour task resolution

project. The members of the same group will be able to collaborate and cooperate at distance and at the same moment. According to certain rules, our tool will allow communication among the users, the production and the distribution of tasks solutions, as well as coordination and a simplified planning of the activities of each.

\section{IMPLEMENTATION}

Our tool is developed like a server application on the Intranet/Internet. In order to guarantee independence compared to a precise operating system, we implemented it by using the languages PHP, HTML and the JavaScript language, and the MySQL database under the server Web Apache. These software resources are free and usable on all platforms (MS Windows, Unix, Linux or Mac OS). Our initial concern is to ensure the greatest possible diffusion of the application for its use by a large audience. From this point of view, it can be easily integrated in a platform of distance learning.

In addition, our tool can be used and managed by no expert teachers in information technology; the simplicity and the facility of use were the essential constraints of design.

The Fig. 2 displays a real scenario of task resolution shows task statement in upper part and the initiated debate by the learners in the lower part. The structure of resolution of the exercise describes the solution in the course of edition as the students see it. From the technical point of view, the presentation of the structure is primarily used to identify parts or positions in the total solution of the exercise. Its exploitation in a cooperative environment makes it possible to coordinate and synchronize the actions of the students. The existence of this structure naturally suggests a whole of operations to exploit it and handle it. The distance learning is a device still at the stage of reflection in the Algerian universities. The observation of the learners of fourth year preparing the engineering degree in data processing, option material and software at the department of Computer Science allowed us to measure their reaction towards the tool. This first experiment revealed that a majority of learners remained refractory towards our tool and that only very few of them managed effectively to benefit from it. This fact can be explained by the common practices characterized by the face-to-face education, which still prevails in manners and behavior ${ }^{[20]}$.

We think that it would be necessary to supplement the adaptation of our tool in accordance with the characteristics of its potential users by an in-depth work of explanation and appreciation. In addition, the designers of the teaching material, teachers and learners must acquire specific competencies to exploit these new suggested technologies. The designers must be trained so that the contents are presented in a convenient way to the collaboration as well as the tutors so that they cope with the collaborative exchanges.

\section{CONCLUSION}

We have presented a tool allowing learners, geographically dispersed, to collaborate in order to 
solve tasks. We have focused on a particular situation: synchronous resolution. We have thus designed a dataprocessing tool facilitating, in one hand, the course of the activity of task collaborative resolution and on the other hand, making the automatic appreciation of the different participants' involvement possible with an aim of determining the participations quality with or without the teacher. The results obtained during the experiment, seem to confirm our assumption of the possibility to automate the process of the involvement appreciation, which is reason to carry further $\operatorname{research}^{[20]}$.

\section{REFERENCES}

1. Nogry S., S. Jean-daubias and N. Guin-duclosson, 2001. La psychologie cognitive au service de la conception de l'environnement d'apprentissage AMBRE. Laboratoire d'Ingénierie des Systèmes d'Information, Université Claude Bernard, Lyon.

2. Kaye, A.R., 1992. Learning together apart. In A.R. Kaye (Ed.), Collaborative Learning through Computer Conferencing. Berlin, Springer-Verlag.

3. Light, P. and V. Light, 1999. Analysing asynchronous learning interaction. Computer mediated communication in a conventional undergraduate setting. In K.L.P. Light (Ed.), Learning with Computers: Analysing Productive Interaction. London, Routledge, pp: 162-178.

4. Rada, R. and W. Wang, 1998. Computer-supported collaborative writing phases. J. Educat. Technol. Sys., 26: 137-149.

5. Fung P., 1996. Issues in project-based distance learning in Computer Science. J. Distance Education/Revue de l'enseignement à distance, Feb., 11.

6. Peal, D. and B.G. Wilson, 2001. Activity theory and web-based training. In B. Khan (Ed.), Webbased training. Englewood Cliffs NJ: Educational Technology Publications, pp: 147-153.

7. George, S., 2002. SPLACH: A computer environment supporting distance project-based learning. Proc. World Conf. on Educational Multimedia, Hypermedia and Telecommunications ED-MEDIA, Denver, Colorado, USA, pp: 588593, June 24-29.

8. George, S., 2003. Analyse automatique de conversations textuelles synchrones d'apprenants pour la détermination de comportements sociaux. Revue STICEF, Vol. 10.
9. Pléty, R., 1996. L'apprentissage coopérant. Collection Ethologie et psychologie des communications, Lyon, ARCI Presse Universitaire.

10. Wilson B. G., 1996. What is a constructivistlearning environment? In B.G. Wilson (Ed.), Constructivist learning environments. Case studies in instructional design Englewood Cliffs, NJ: Educational Technology Publications, pp: 3 - 8 .

11. Djoudi, M. and S. Harous, 2002. An environment for cooperative learning over the Internet. Intl. Conf. Artificial Intelligence (IC-AI'2002), Las Vegas, Nevada, USA, Jun. 24-27.

12. Standridge, C.R. and D.B. Wortman, 1981. The simulation data language (SDL). Simulation J., pp: 55-88.

13. Rheingold, H., 1993. Les communautés virtuelles. Paris, Edition Addison-Wesley.

14. Zidat, S., M. Djoudi, A. Zidani and S. Talhi, 2004. Collaborative resolution of tasks in situation of distance learning. Intl. Arab Conf. on Inform. Technol., Constantine, Algeria, Dec., 12-15.

15. Betbeder, M.L. and P. Tchounikine, 2003. Structuring collective activities with tasks and plans. Proc. 3rd IEEE Intl. Conf. Advanced Learning Technologies, Athens, Greece.

16. Taurisson, N. and P. Tchounikine, 2004. Supporting a learner community with software agents. Educat. Technol. Soc., 7: 82-91.

17. Kuutti, K., 1997. Activity Theory as a Potential Framework for Human-Computer Interaction Research. In B.A. Nardi (Ed.), Context and Consciousness: Activity Theory and HumanComputer Interaction. Massachusetts, The MIT Press, pp: 17- 44.

18. Kendon, A. and A. Ferber, 1973. A Description of Some Human Greetings. In Comparative Ecology and Behaviour of Primates. Michael, R.P., Crook, J.H., (Eds.), London, Academic Press, pp: 591-668.

19. Michinov, N., C. Primois and M.C. Gravey, 2003. Scénarisation et accompagnement d'une action de formation collaborative à distance: Une illustration de la méthodologie $\mathrm{Cl} @$ p. Intl. J. ISDM.

20. Zidat S. and M. Djoudi, 2006. Online Evaluation of Ibn Sina Elearning Environment. Information Technology Journal Vol. 5(3), pp 409-415. 